\title{
Intervenção para desenvolvimento de enfermeiros gerentes em um hospital público na perspectiva da pesquisa ação
}

Intervention for managers' nurse development in a public hospital based on action research

Intervención para el desarrollo de los enfermeros gerentes en un hospital público en la perspectiva de la investigación-acción

Kátya Alexandrina Matos Barreto Motta ${ }^{\mathrm{I}}$, Denize Bouttelet Munari ${ }^{\mathrm{II}}$, Fernanda Costa Nunes ${ }^{\mathrm{II}}$

\section{RESUMO}

Investigação cujo objetivo foi descrever o processo de desenvolvimento de enfermeiros gerentes para melhor desempenho profissional. Pesquisa ação realizada com 24 enfermeiros em hospital público em Goiânia/Go. Os dados foram coletados no decorrer de uma intervenção norteada pelo ciclo vivencial de aprendizagem e a dinâmica de grupo. Os dados foram registrados em diário de campo, gravações de áudio, analisados descritivamente, considerando o valor do significado expresso nas falas dos participantes e do movimento grupal. A intervenção produziu no grupo reflexões sobre a postura gerencial, a partir de diagnóstico sobre si mesmo, identificação dos pontos fortes daqueles a serem desenvolvidos, além de sinalizar as possíveis mudanças necessárias. A pesquisa ação e o ciclo vivencial de aprendizagem mostrou-se como ferramenta eficiente no processo de qualificação dos enfermeiros, pois possibilitou avançar para além da dimensão cognitiva que envolve o aprendizado gerencial e permitir o alcance dos níveis emocional e atitudinal.

Descritores: Administração de Serviços de Saúde; Serviço Hospitalar de Enfermagem; Recursos Humanos de Enfermagem.

\section{ABSTRACT}

This research aimed to describe the managers' nurse development process to a better professional performance. The method was the Action Research with 24 nurses from a public hospital in Goiania/Goias/Brazil. Data were collected through meetings that was guided by the experimental learning cycle and group dynamics, and recorded in a field-notes diary and audio recordings. These data were organized and descriptively analyzed considering the participants' speeches' value meanings and also the group dynamics'. From the intervention resulted thoughts about the manager's position, the diagnosis about itself and strengths and those that require improvement, besides to indicate necessary changes. The Action Research and the learning cycle proved to be an effective tool for nurses' qualification, because made possible to be ahead of the cognitive dimension that involves the management learning and to allow the extent of emotional and attitudinal levels.

Descriptors: Health Services Administration; Nursing Service, Hospital; Nursing Staff.

\section{RESUMEN}

Investigación que objetivó describir el proceso de desarrollo de enfermeros gerentes para mejor desempeño profesional. Investigación-acción con 24 enfermeros de un hospital publico en Goiânia/GO. Los datos fueron recogidos durante una intervención guiada por lo ciclo del aprendizaje experiencial y dinámica de grupos registrados en un diario de campo y grabaciones de audio. Posteriormente fueron organizados y analizados descriptivamente considerando el valor del significado de los discursos de los participantes y el movimiento del grupo. La intervención resultó en reflexiones por el grupo en relación a la postura gerencial, desde el diagnóstico de sí mismo y identificación de los puntos fuertes de los que necesitan mejorar y indicar los posibles cambios necesarios. La investigación-acción y el ciclo de aprendizaje demostró ser una herramienta eficaz en el proceso de calificación de enfermeros siendo posible avanzar asta más allá de la dimensión cognitiva del aprendizaje gerencial y permitir el alcance de los niveles emocionales y actitudinales.

Descriptores: Administración de los Servicios de Salud; Servicio de Enfermería en Hospital; Personal de Enfermería.

\footnotetext{
I Psicóloga, Doutora em Ciências da Saúde. Professor Assistente, Faculdade Cambury. Goiânia, GO, Brasil. E-mail: katyadesenvolverh@hotmail.com.

II Enfermeira, Doutora em Enfermagem. Professor Titular, Faculdade de Enfermagem, Universidade Federal de Goiás. Goiânia, Go, Brasil. E-mail: denize@fen.ufg.br.

III Psicóloga, Mestre em Ciências da Saúde. Professor Horista, Faculdade Araguaia. Goiânia, GO, Brasil. E-mail: desenvolve.rh@hotmail.com.
} 


\section{INTRODUÇÃO}

Ao se considerar a posição estratégica dos enfermeiros que atuam na gestão dos serviços de enfermagem nos hospitais, é fundamental que competências gerenciais sejam desenvolvidas para a construção de um sistema de gestão compatível com as demandas das organizações hospitalares e com as tendências da política de saúde ${ }^{(1-5)}$.

Quando a formação dos enfermeiros tem como base o desenvolvimento dessas competências, a atuação desses profissionais tendem a produzir transformações significativas, pois se fundamentam em ações efetivas e compartilhadas com a equipe de enfermagem, especialmente pela importância estratégica que essa tem na dinâmica hospitalar ${ }^{(2,6)}$.

Uma revisão de literatura sobre as tendências contemporâneas de gestão do contexto organizacional hospitalar apontam que, o estilo de liderança dos enfermeiros deve se basear em modelos inovadores, que sejam capazes de integrar a qualidade do cuidado, a satisfação da equipe e os objetivos organizacionais ${ }^{(1-4,6-9)}$. Estudos também apontam que essa tendência exige a superação dos modelos de gestão tradicionais e a incorporação de outros mais flexíveis que valorizem e motivem as pessoas ${ }^{(2-5)}$. Outros destacam ainda que esses devam possibilitar o desenvolvimento de atitudes éticas e comprometidas com a expansão da autopercepção ${ }^{(9-11)}$.

A necessidade de repensarmos os processos de formação do enfermeiro, tanto no contexto acadêmico como no da educação continuada, de modo que esses permitam aos profissionais experimentar modelos que ultrapassem aqueles tradicionais e que estimulem novas atitudes na gestão também são tema de vários estudos $^{(5,10-12)}$. Vale o destaque, finalmente, aqueles que sugerem que a formação de lideranças em enfermagem devem também fortalecer os enfermeiros no manejo do campo relacional, em particular, no desenvolvimento de pessoas e gerenciamento de conflitos $^{(3,5,11,13-14)}$.

No presente trabalho focalizamos, especificamente, esse ultimo aspecto, a partir da compreensão de que esta é uma área ainda por se desenvolver no campo da formação/capacitação dos enfermeiros. Embora seja muito propagada a ideia da necessidade de desenvolvimento de habilidades gerenciais para se lidar com a dimensão atitudinal das lideranças em enfermagem, são poucos os estudos que se ocupam desse aspecto particular.
A partir do interesse de um grupo de gerentes de enfermagem de um hospital público, que definiu em suas metas implantar o processo de gestão participativa, esse estudo foi proposto com o objetivo de descrever o processo de desenvolvimento de enfermeiros gerentes para melhor desempenho profissional.

\section{METODOLOGIA}

Para a condução do estudo realizamos uma pesquisa ação, definida como um método de base empírica, organizada e desenvolvida a partir de uma ação, na qual pesquisadores e participantes apresentam-se envolvidos de modo participativo ${ }^{(15)}$.

O processo de investigação foi mediado por uma intervenção grupal, baseada nos pressupostos da dinâmica de grupo ${ }^{(16-17)}$.

O estudo foi realizado entre agosto de 2007 e junho de 2008, em um hospital público de Goiânia/GO. Foram convidados a participar da pesquisa os enfermeiros gerentes vinculados a Diretoria de Enfermagem, suas assessorias e aqueles que desempenhavam atividades na coordenação das diversas unidades do hospital. Foram considerados critérios de inclusão: ter no mínimo um ano em função de coordenação, gerência ou assessoria, ter disponibilidade de acompanhar o cronograma definido para o processo investigativo, concordar com o método de trabalho focado na intervenção grupal.

Os participantes foram esclarecidos quanto aos objetivos da pesquisa e as condições para participação na mesma, assinando o Termo de Consentimento Livre e Esclarecido. Os procedimentos adotados na condução da investigação seguiram as etapas previstas para o processo da pesquisa ação(15), sendo a primeira fase exploratória ou diagnóstica tendo inicio no primeiro encontro momento em que foram discutidos os objetivos do estudo, sua articulação aos interesses do grupo e do levantamento das necessidades para a composição do plano de intervenção grupal. Nesse momento, foi construído o contrato psicológico, para operacionalizarmos os encontros, definindo datas, local, horário, dias da semana e regras de participação.

Foram definidos pelo grupo a participação em 20 encontros quinzenais de 4 horas em média totalizando 80 horas de intervenção, cujo conteúdo é discriminado no Quadro 1. 
Quadro 1: Cronograma e tema dos encontros da intervenção e pesquisa. Goiânia, GO, 2009.

\begin{tabular}{|c|c|}
\hline Encontro & Temática \\
\hline 10 Encontro & $\begin{array}{l}\text { Integração e nucleação do grupo } \\
\text { Diagnóstico da demanda do Grupo } \\
\text { Levantamento das expectativas dos membros do grupo } \\
\text { Contrato psicológico de convivência } \\
\text { Apresentação do Plano de Desenvolvimento do Gerencial }\end{array}$ \\
\hline $\begin{array}{l}2^{\circ} \text { Encontro } \\
3^{\circ} \text { Encontro }\end{array}$ & $\begin{array}{l}\text { Desenvolvimento intra e inter pessoal e grupal } \\
\text { Integração e nucleação do grupo } \\
\text { Reflexão sobre respeito, criatividade, cooperação e comprometimento }\end{array}$ \\
\hline 40 Encontro & Processo de percepção \\
\hline $5^{\circ}$ Encontro & Desenvolvimento de papéis: pessoais e profissionais \\
\hline $6^{\circ}, 7^{\circ}$ e $8^{\circ}$. Encontros & Estratégias de motivação \\
\hline 90 Encontro & Processo de Comunicação intra e inter pessoal \\
\hline $10^{\circ}$ Encontro & Processo de Comunicação e feedback \\
\hline $11^{\circ}$ Encontro & Processo de mudanças - resistência, conflito, equilíbrio e crise \\
\hline $12^{\circ}$ Encontro & Processo de mudança - quebra de paradigmas \\
\hline $\begin{array}{l}13^{\circ}, 14^{\circ} \text { e } 15^{\circ} \\
\text { Encontros }\end{array}$ & $\begin{array}{l}\text { Processo de liderança: } \\
\text { Posturas gerenciais e poder } \\
\text { Delegação e otimização das atividades e resultados }\end{array}$ \\
\hline $16^{\circ}$ Encontro & $\begin{array}{l}\text { Apresentação das competências para o desempenho da produtividade e alcance dos } \\
\text { resultados }\end{array}$ \\
\hline $17^{0}$ Encontro & Implementação dos planos de ações \\
\hline $18^{\circ}$ e $19^{\circ}$ Encontros & Acompanhamento e análise de resultados \\
\hline $20^{\circ}$ Encontro & Encerramento, integração do grupo e avaliação do plano de desenvolvimento gerencial \\
\hline
\end{tabular}

A fase intermediária consistiu no trabalho dos temas de interesse do grupo e a análise dos processos vividos pelos participantes mediados pelo ciclo da aprendizagem vivencial- $\mathrm{CAV}^{(18)}$. Nesse ciclo, o primeiro momento do processo é a vivência de uma situação ou atividade que pode ser a solução de problemas, jogos, exercícios vivenciais, dramatizações, simulações, filmes, entre outras técnicas. Na sequência da vivência, o grupo é convidado a analisar o processo vivido.

Nessa ocasião é importante que todos os membros do grupo tenham espaço e abertura para expressar seu posicionamento sobre a experiência, sendo estimulado a auto-exposição e feedback entre os integrantes ${ }^{(18-20)}$. Esse processo permite ao coordenador a percepção do caminho escolhido pelo grupo para analisar sua vivência e na sequencia é sua tarefa subsidiar o grupo com informações e fundamentos teóricos que permitam a sistematização e elaboração de mapas cognitivos individuais, vinculados aos processos vividos. Com esse tipo de intervenção os membros do grupo conseguem refletir e se conscientizar dos aspectos inadequados ou problemáticos que carecem de mudança e reformulação. Após o momento de conceituação é possível avançar para a conexão e correlação com a realidade, onde o coordenador convida o grupo a comparar os aspectos vividos e teorizados com as situações práticas de trabalho e vida em geral ${ }^{(18-20)}$.

A exploração do CAV permite ao pesquisadores e participantes do grupo integrar as dimensões cognitiva, emocional, atitudinal e comportamental da aprendizagem, buscando sempre a correlação entre teoria e aplicação no cotidiano, com a proposta do aprender a aprender, aprender a dar ajuda e a participação eficiente em grupos ${ }^{(18-20)}$.

Embora o processo de avaliação seja processual, na fase final da intervenção, em particular nos últimos encontros, o grupo teve como meta avaliar todo o seu processo de desenvolvimento.

Os encontros foram conduzidos por duas pesquisadoras, Especialistas em Consultoria e Gestão de Grupos, em sistema de co-coordenação. Os dados foram coletados mediante registro em diário de campo e gravação em fita cassete dos acontecimentos vivenciados, processados e relatados pelo grupo. Ao final de cada encontro as pesquisadoras em reunião com a orientadora analisavam, em conjunto, os direcionamentos da intervenção, realizando assim as adequações necessárias para dar continuidade a proposta de capacitação dos enfermeiros gerentes.

Após a transcrição das gravações e organização das anotações do diário de campo, os registros foram 
submetidos a uma leitura exaustiva, com a finalidade de destacarmos as categorias analíticas que permitissem entender como se deu o processo grupal.

Foram analisadas as anotações do diário de campo, as observações dos comportamentos observados, o relato dos sentimentos expressos, latentes e manifestos, com a intenção de se identificar as situações vivenciadas pelo grupo ao longo de seu processo. A análise dos dados foi apoiada na perspectiva da investigação qualitativa que, considerando o valor do significado expresso nas falas dos participantes bem como o movimento do grupo, permitiu a descrição analítica do processo grupal e interpretações fidedignas dos fatos vivenciados. A pesquisa foi autorizada pela Diretoria do hospital e aprovado pelo Comitê de Ética, protocolo $\mathrm{n}^{\circ}$ 099/07.

\section{RESULTADOS E DISCUSSÃO}

Participaram do estudo 24 gerentes, desses 12/50\% já ocuparam cargos gerenciais e 22/91,6\% eram do sexo feminino, com média de idade de 44 anos. No que se refere ao tempo de trabalho na instituição, o tempo mínimo era de cinco anos e o máximo de 33 anos. A maioria dos participantes $(22 / 91,6 \%)$ possuía pelo menos um curso de pós-graduação em nível de especialização em diversas especialidades, e uma pequena parcela do grupo $5 / 20,8 \%$ cursou mestrado.

Para apresentar a análise do processo do grupo durante a intervenção, destacamos os resultados em cada etapa da pesquisa ação, denominando os movimentos como episódios que sintetizam a trajetória percorrida pelo grupo.

\section{Etapa exploratória e diagnóstica: a nucleação do grupo e a definição dos rumos da investigação}

Os encontros iniciais marcaram a nucleação e a percepção do grupo sobre si mesmo e, a definição dos rumos da investigação, haja vista que esse é um dos quesitos da pesquisa ação, pois o objetivo da mesma é definido em comum acordo com o grupo estudado na pesquisa ${ }^{(15)}$.

De modo geral os participantes, mostraram-se dispostos e comprometidos com a proposta de, durante a intervenção, desenvolver técnicas para o gerenciamento das unidades, por meio do processo de apreensão do conhecimento discutido, análise crítica do mesmo e aplicação imediata na prática, por meio de planejamento a ser elaborado e implementado durante os vinte encontros.

Episódio I: o primeiro encontro foi dedicado à construção do contrato de convivência grupal e a sua aprovação. Esse contrato deve ser construído e validado por todo o grupo, os assuntos tratados devem ser de consentimento de todos os membros, para que haja o comprometimento com as regras durante os encontros ${ }^{(19)}$.

O conteúdo do contrato expressou as espectativas do grupo com relação ao processo que iria vivenciar durante a intervenção como ilustra o Quadro 2.

Quadro 2: Elementos presentes no contrato de convivência construído pelo grupo. Goiânia, GO, 2009.

\begin{tabular}{|c|l|}
\hline $\begin{array}{c}\text { O que esperamos } \\
\text { dessa atividade? }\end{array}$ & $\begin{array}{l}\text { Muita discussão; alegria; aprendizado; amor; solidariedade; organização; comprometimento } \\
\text { com o grupo que ficou; ir até o fim; muita felicidade; amizade; respeito; lanche; presença de } \\
\text { todos; maturidade; alguém responsável pelo lanche; bom humor; união sincera; integração; } \\
\text { que o conteúdo teórico seja repassado ao grupo, como também o material didático; o } \\
\text { certificado do curso seja entregue no dia; dinamismo no curso; objetividade; sucesso; filme } \\
\text { com pipoca e guaraná; crescimento profissional; sigilo ético; celular no silencioso. }\end{array}$ \\
\hline $\begin{array}{c}\text { O que não } \\
\text { gostaríamos que } \\
\text { ocorresse nessa } \\
\text { atividade? }\end{array}$ & $\begin{array}{l}\text { Que ninguém desista; não tenham faltas desnecessárias; fofoca; tarefas de casa; que não } \\
\text { seja desviado o tema central de discussão; choro excessivo; dramatização; sensacionalismo; } \\
\text { exibicionismo; muro de lamentações; falsidade; tristeza; intolerância; falas desnecessárias; } \\
\text { pessimismo; desânimo; atrasos (zero tolerância); quebra de contrato; conversas paralelas; } \\
\text { celular ligado; atender celular na sala; impaciência. }\end{array}$ \\
\hline $\begin{array}{c}\text { Que perguntas } \\
\text { gerenciais } \\
\text { desejamos que }\end{array}$ & $\begin{array}{l}\text { Construir estratégias conjuntas de gerenciar a equipe, administrar as escalas de serviço, } \\
\text { entre outros; Elaborar programas de motivação, para estimular o comprometimento da } \\
\text { equipe com a instituição, com a unidade e com o usuário; } \\
\text { sejam respondidas? }\end{array}$ \\
\hline Melhorar os processos de comunicação intra e inter setores.
\end{tabular}

A coordenação priorizou uma atividade em que o contrato pudesse ser discutido de forma circular, interativa e integrada. Os teóricos que discutem sobre o tema ${ }^{(16,19)}$ sinalizam a necessidade de construir democraticamente as regras de convivência e trabalho do grupo, assegurando o respeito e delimitando os limites de convivência entre todos. 
Episódio II: O grupo foi convidado a vivenciar uma atividade coletiva que envolvia a todos, embora cada participante pudesse manter a sua individualidade. Tratava-se da construção de um painel que deveria retratar a visão de como aquele grupo sai via naquela ocasião. O produto final expressava um grupo pulsante, cujo material projetivo representava a vida, a alegria, os sentimentos de participação e de estarem juntos. As imagens mais significativas foram o sol, a luz, a vida e a natureza. A análise do material projetivo produzido sinalizou um grupo que se mostrou naquele instante como uma terra fértil, um grupo vivo ${ }^{(17,19)}$.

Essa atividade refletiu o desejo da convivência e da presença do outro, o que se reforçava também a tarefa de discutir as habilidades gerenciais. As falas que acompanharam a elaboração do material remetiam à idéia de que a gerência não era tarefa fácil, em razão das responsabilidades diárias de lidar com a sistematização dos processos nas unidades, assegurarem a qualidade e a humanização da saúde. Nesse momento - grupo demonstrou suas forças impulsoras, o seu potencial de superar os aspectos restritivos coexistentes do ambiente labora ${ }^{(11,13,16-17,19)}$.

Episódio III: Em outro momento foi solicitado a cada participante que desenhasse o contorno de seu corpo em uma grande folha de papel pardo e o preenchesse por meio de recortes de revistas ou desenhos as representações de seus sonhos, desejos, ideologias, projetos, sentimentos e vontades, tal atividade tinha o objetivo de levar os integrantes a uma imersão no contexto intrapessoal.

A análise do conteúdo das imagens presente nos painéis produzidos pelo grupo permitiu inferir que os participantes conseguiram expressar seus sonhos, desejos e expectativas de vida pessoal, familiar e profissional.

Nessa projeção, o grupo manifestou o desejo de ter uma carga menor de trabalho e de ser mais respeitado no hospital, de poder viajar mais, de ter mais momentos de autocuidado, de passar mais tempo com a família, de ter menos responsabilidades e preocupações no cargo gerencial, e de ser mais bem remunerado profissionalmente. Tais movimentos mostram a contradição do grupo em querer manter-se no cargo de gestor, mas idealizando que o trabalho fosse mais leve, especialmente por requerer muita responsabilidade, desejando assim uma vida profissional menos estressante.
O processamento do ciclo da aprendizagem vivencial levou o grupo a perceber que estava distante de conquistar muitos dos desejos expressos tais como: descansar, ter mais lazer ou mesmo se envolver em atividades profissionais e pessoais mais prazerosas.

Esse resultado denuncia de certo modo uma realidade laboral dos enfermeiros gerentes caracterizada por um cotidiano carregado de situações reativas e emergenciais que exigem por parte dos mesmos soluções imediatas que, gera grande desgaste físico e emocional tal como indicam outros estudos ${ }^{(6-7,14)}$. O fato dos gerentes conviverem com constantes cobranças, de exigências para resolutividade em prazos mínimos, torna a situação um círculo vicioso de stress e tensão. Nesse campo de atuação dos participantes da pesquisa estão presentes mais forças que restringem suas intervenções do que forças que valorizam suas realizações ${ }^{(9-11,16)}$

O comportamento observado do grupo durante a discussão, apontou que ao tomar consciência da sua realidade, este se coloca numa postura defensiva e pouco colaborativa. Esse movimento contrasta com o vivido durante a fase diagnóstica, em que o grupo se coloca disposto a trabalhar suas necessidades, tornar o trabalho mais leve e a consolidar a parceria entre as equipes. Os relatos vividos no episódio III mostram que há dificuldade para parcerias na prática e que a busca do trabalho coletivo não é tão simples ${ }^{(7)}$.

o grupo percebeu a complexidade que envolve a tarefa de mudança de atitude na ação gerencial, por envolver além da dimensão técnica da função, aspectos éticos, relacionais e valores pessoais ${ }^{(1,5-7,9-14)}$, assim como o jogo de poder presente em toda organização ${ }^{(13-}$ $14,16,20)$.

Por essa razão, os encontros foram de certa forma terapêuticos e lúdicos, oferecendo suporte ao grupo, para exposição de suas dificuldades pessoais e profissionais. Ao perceber as restrições impostas pelo modelo organizacional, que limitam e comprometem a autonomia dos gerentes, o grupo se afastou da proposta inicial da investigação de investir no estudo das questões relativas à gestão e voltou-se para o aproveitamento dos momentos de relaxamento que a intervenção proporcionava.

Esse movimento fechou a etapa diagnóstica e de nucleação do grupo, indicando que as pesquisadoras teriam pela frente, o desafio de incentivar os participantes a sair da situação de fuga e angustia de não conseguir pensar em soluções diante da 
complexidade da dinâmica organizacional, as quais estavam inseridos ${ }^{(11,16-17,19)}$.

\section{Etapa intermediária: análise do processo vivenciado pelo grupo a partir do caminho escolhido.}

Episódio IV: diante do movimento de fuga e angústia do grupo, a coordenação buscou aplicar técnicas que levassem os participantes a reflexão sobre os aspectos que envolviam a situação de impasse diante da proposta inicial da intervenção de aprofundar o estudo e aplicação prática de habilidades para o desenvolvimento gerencial, diante do desejo do grupo de permanecer vivenciando um momento terapêutico, de autoconhecimento, mas sem garantir disposição para implementar mudanças.

Uma dessas técnicas solicitava ao grupo que, em duplas, realizassem a seguinte tarefa: "relate ao seu parceiro uma pequena história, é preciso contá-la do começo ao fim garantindo que o seu colega entendeu o que foi dito". Sem que o outro soubesse, uma pessoa de cada dupla recebeu um comando por escrito indicando a sua posição diante da tarefa, tais como: fique em silêncio; critique tudo; converse e não deixe o colega falar nada; faça de conta de que não liga para o que o colega fala; fique no celular; mude de assunto toda vez que o colega fala.

Essa atividade levou os gerentes a vivenciarem situações, muito semelhantes as do seu dia a dia profissional, em que buscavam se comunicar, mas não era nem entendidos e nem ouvidos. A vivência suscitou no grupo a percepção e a discussão de que era preciso melhorar a comunicação tanto entre as equipes de trabalho quanto entre os setores do hospital. Além disso, mostrou que é necessário sintonizar-se com o ponto de vista do outro, se queremos implementar mudanças, respeitar o outro, para ser também por ele respeitado.

A comunicação entre equipes de trabalho é um tema amplamente discutido por pesquisadores que estudam as tendências da gestão no contexto hospitalar ${ }^{(2-3,6-7)}$ e que sinalizam ser é fundamental a necessidade de adoção de modelos de gestão mais adequados a vida contemporânea e aos pressupostos da política nacional de saúde ${ }^{(3,7,10)}$. Os modelos baseados na gestão compartilhada desenvolvem mais a capacidade reflexiva, mais capacidade de interferir sobre os fatores estruturais externos e internos à organização, como a cultura organizacional ou a personalidade e o caráter dos servidores $^{(7,20)}$.
A discussão do grupo frente a atividade conduziu a reflexão dos processos de comunicação na organização, em particular a escrita onde o processo é ainda mais complexo. Embora os participantes recebam da organização hospitalar a mesma normativa, cada gerente interpreta e conduz o seu cumprimento de um modo diferente ou agilizando a comunicação ou tornando a ainda mais morosa.

O grupo pode perceber que a comunicação é falha, e muitas vezes limitada pela falta de agilidade e quebra no fluxo de transmissão o que traz prejuízos a todos os envolvidos na situação. Além disso, refletiu sobre o quanto as cenas vivenciadas pela técnica trazida pelas coordenadoras refletem o cotidiano do hospital, ressaltando as forças restritivas que impedem que o grupo funcione como uma totalidade dinâmica ${ }^{(16-17,19)}$ e mantém o comportamento do enfermeiro sempre em defensiva, diante da ameaça de se mostrar incompetente.

Episódio V: com a abertura do grupo para perceber o seu modo de funcionamento e, portanto, de ter espaço para olhar para a dinâmica de suas relações foi proposta uma outra atividade em que o grupo precisava realizar a construção coletiva do boneco de um homem. Para isso o grupo foi dividido em três subgrupos onde cada um tinha partes específicas para construir. A tarefa foi dividida em três fases: planejamento, execução e montagem. Após serem dadas as instruções por escrito contendo cada detalhe da construção bem como ter sido disponibilizado todo o material necessário, a coordenação passou a acompanhar o processo sem oferecer nenhuma outra instrução.

Cada grupo demonstrou envolvimento em sua própria tarefa. Ao término da atividade foi solicitado ao grupo que juntasse as partes para montar o produto final. Ao analisar o resultado do trabalho coletivo, o grupo avaliou que, apesar de gostar do boneco construído, alguns detalhes, tais como: sapatos, ombros, quadril e pernas destoavam em tamanho, estilo e cor diferentes.

O processamento do $\mathrm{CAV}^{(18-19)}$ levou o grupo a percepção de que faltou planejamento, comunicação, delegação de tarefas, identificação de recursos e integração entre os grupos. Ficou clara a percepção de que para realizar o boneco a contento, os participantes deveriam, primeiramente, na etapa do planejamento, ter identificado os recursos e materiais necessários, bem como levantar os potenciais das pessoas e o tempo 
disponível para execução da tarefa. O grupo percebeu então que era essencial ter havido comunicação antes e durante o processo de construção entre os grupos, principalmente porque, no início da tarefa os subgrupos não se ativeram à leitura das instruções de modo detalhado. Assim, não se deram conta da complexidade das instruções que levariam a um resultado mais satisfatório.

O resultado da atividade vivenciada e analisada pelo grupo levou a percepção de que a produção do boneco refletia fortemente o funcionamento da equipe gerencial no dia a dia no hospital. Os participantes se deram conta que no ritmo acelerado de execução de atividades, não se organizavam para realizar um planejamento. Outro ponto destacado foi que, embora nos subgrupos o clima lúdico tenha predominado durante a elaboração da tarefa, esse não foi compartilhado com os outros, pois não houve integração entre os subgrupos. Essa falta de interação na atividade refletiu também o que ocorria no contexto laboral dos gerentes enfermeiros ${ }^{(2,6-7)}$ pois em geral, não havia integração entre as unidades de trabalho do hospital por várias questões, tais como tempo, distância, diversidade na assistência ao usuário, entre outros.

A vivência de construção do boneco levou o grupo ao cansaço e estresse. Diante da realidade percebida o grupo expressou desejo de não atrair "mais" responsabilidades para si mesmo. Por outro lado, não percebeu que se optasse por aceitar o objetivo inicial da pesquisa, de se apropriarem dos fundamentos e conhecimentos gerenciais oferecidos pelas coordenadoras, poderiam melhorar o seu desempenho e, por conseguinte, aliviar sua carga profissional.

Episódio VI: as pesquisadoras percebendo a dificuldade do grupo em manter a proposta inicial de construir estratégias focadas na gestão, fez um mapeamento e análise dos movimentos que percebia no comportamento dos enfermeiros gerentes e apresentou-o ao grupo com a intenção de propor uma leitura e reflexão sobre o processo de desenvolvimento do grupo diante da proposta inicial da pesquisa.

De acordo com os participantes a intervenção era percebida como momento de "recreio", por ser um espaço em que era possível manifestar emoções e obter suporte especializado, em um ambiente favorável a reconstrução da autoestima, a recomposição da confiança e da capacidade gerencial, para continuar lidando com a rotina acelerada do hospital como evidenciam os seguintes depoimentos:

Às vezes deixo de fazer milhares de coisas lá fora para estar aqui. Meu compromisso em estar aqui é muito grande, estar aqui também é alívio.

Aqui é lugar de pensar e refletir.

Aqui é espaço para cada um avaliar a si mesmo e as suas ações.

Travamos discussões produtivas.

As atividades são realizadas em clima lúdico.

Há empenho e capricho nas tarefas propostas.

o grupo cuida de si, prepara super lanches, traz alimentos e doces, serve café na sala, cuida um do outro e se preocupa com os colegas.

Cada encontro do processo de capacitação gerencial foi considerado pelo grupo como momento de pausa e distanciamento do ambiente de trabalho. Nessas ocasiões os participantes experimentaram a oportunidade de descansar e se ausentar do clima de cobrança, pressão e tensão vividas na instituição.

Ao reconhecer sua dinâmica, o grupo fez imersões e refletiu sobre sua postura gerencial. Assim, retomou temas como: usar a autoridade com a equipe; retomar o compromisso com as atividades; assegurar que a escala de trabalho seja cumprida; atender as demandas individuais; melhorar as competências gerenciais; ser mais flexível; parar de agir sem pensar, ser menos impulsivo; ter coragem e agir com mais firmeza; ter jogo de cintura, entre outros.

Ao se dispor a pensar nesses aspectos o grupo expandiu sua visão gerencial a ponto de perceber que, não existe um perfil gerencial ideal, nem tão pouco um comportamento padrão. O grupo compreendeu que, é preciso ampliar o conhecimento sobre si para construir as suas próprias competências.

Essa construção é um processo sempre em desenvolvimento que perpassa pela trajetória de tomar consciência e buscar mudança de atitudes ${ }^{(11-13,16-17,19)}$. Nesse sentido, o trabalho realizado durante a investigação pareceu fazer sentido e tomar contornos mais claros do seu alcance, pois esse processo de tomada de consciência é justamente o objetivo maior de uma pesquisa ação ${ }^{(15-17)}$.

A construção de novos modelos de gestão passa, necessariamente, por uma ampla mudança na forma de pensar e agir das pessoas que ocupam cargos e funções chaves nesse processo, pois nela se inscrevem grandes 
desafios humanos ${ }^{(2-5,7,9,13,20)}$. Estes estão relacionados a disposição para rever aspectos que envolvem a formação técnica do gestor, e também a formação humana, de valores, de crenças e de atitudes diante do poder e do lugar que se ocupa na direção das atividades de um serviço ${ }^{(1,3,7,10,20)}$.

\section{Etapa Final: avaliação do processo vivido}

Epílogo: Os últimos encontros foram destinados ao fechamento do trabalho e avaliação da produção e convivência em torno das 80 horas da intervenção. Os temas mais presentes giravam em torno da idéia de que o gerente precisava ocupar o lugar dele, assumindo suas responsabilidades na gestão da equipe, sendo o representante da unidade. O grupo parece recuperar a idéia da importância do sentimento de pertença(11,13,1617,19), fundamental a sobrevivência de qualquer grupo humano, o que tinha sentindo particular, já que se tratava da fala daqueles que eram responsáveis pelos serviços.

Considerando a importância da percepção do coordenador, no caso os enfermeiros gerentes, acerca da sua equipe, o grupo estudado se mostrava sensibilizado a ver e ouvir as pessoas que compõe sua equipe de trabalho, como sujeitos que possuem expectativas, motivações, necessidades, desejos e demandas diferenciadas, e que, portanto, exigiam abordagens múltiplas e complexas. Foi essencial ao grupo o aprendizado de que o gerente precisa usar da sua autoridade, sem autoritarismo, dosando bom senso e assertividade ${ }^{(3,11,6-7,10)}$.

Outro aprendizado relevante, sinalizado pelo grupo como resultante desse processo, foi a conscientização de que o gerente da equipe é responsável por promover um ambiente favorável para o desenvolvimento do trabalho, oportunizando a cooperação, a integração, a colaboração e a participação de todos nos serviços oferecidos pelo seu setor ${ }^{(2-9)}$.

A importância da ação do enfermeiro gerente na gestão dos processos de sistematização da assistência de enfermagem e de educação continuada, foi outra percepção do grupo que vê seu papel singular no processo de ensinar, acompanhar, apoiar e cobrar a execução eficiente dos procedimentos e protocolos adotados pela organização, com vistas a busca da excelência e melhoria da qualidade do serviço ${ }^{(6,8)}$. O grupo reconheceu a importância de adotar uma postura competente, sendo mais flexível para perceber as necessidades de seus colaboradores, bem como estar aberto as contribuições e experiências destes, além de estar disponível para a convivência com os pares que não fazem parte do mesmo grupo profissional.

A fala do grupo refletia finalmente na aprendizagem significativa de que o gerente precisa assumir as atribuições que são inerentes ao seu cargo, participando efetivamente das discussões e encaminhamentos das situações ocorridas em seu contexto de trabalho. Assim, deve estar ciente do que ocorre em sua unidade, para facilitar o processo de comunicação organizacional e demonstrar compromisso e comprometimento com o que foi decidido em conjunto. $E$, finalmente, convidar $e$ incentivar sua equipe para participar ativamente, adotando uma postura gerencial transparente e justa, dando exemplo com atitudes éticas ${ }^{(2-6,9)}$. Quando necessário, pode e deve dizer não, sem agredir os outros, utilizando sua autoridade na medida da razão e não da emoção(17).

\section{CONSIDERAÇÕES FINAIS}

Ao se retomar o objetivo deste estudo que foi o de descrever o processo de desenvolvimento de enfermeiros gerentes para melhor desempenho profissional temos clareza da relevância da experiência para o grupo participante, para as pesquisadoras e para a instituição envolvida.

O grupo de enfermeiros investigado conseguiu produzir reflexões profundas sobre a sua postura como gerente, pois teve condições de comparar o seu perfil com os requisitos de mais adequados ao cargo gerencial, culminando na certeza de que precisavam mudar. O grupo de enfermeiros gerentes foi capaz de elaborar um diagnóstico sobre si mesmo, mapeando seus pontos fortes e os seus pontos a desenvolver, verticalizando em todas as dimensões da sua atuação profissional.

Durante a pesquisa, o grupo não conseguiu articular nenhuma ação em direção a mudança efetiva, tais como elaborar um plano de ação para a unidade, adotar um programa de motivação para implementar em sua unidade ou mesmo assegurar um padrão de gestão. Porém, sinalizou ao longo da atividade que estava mais claro onde, e como, poderiam agir, pois dispunham de elementos teóricos mais consistentes.

Os desejos expressos no inicio da nucleação do grupo de ter uma vida mais leve e um trabalho com menos sobrecarga, dificilmente poderão ser atingidos, com processos de trabalho conduzidos com desperdício 
de tempo e de material, com desgaste físico, e com um planejamento ineficiente.

O grupo vislumbrou o seu potencial em direção à mudança, sem, no entanto, alçar voos mais ousados na tentativa de efetivar o processo de transformar a si mesmo. O discurso da mudança é presente, mas forças restritivas não permitem que grandes avanços sejam concretizados. Talvez a maior delas, seja o fato de que toda mudança envolve perdas e ganhos, além de exigir muito desprendimento pessoal.

A tendência do grupo foi ficar mais na nucleação e vivenciando em sua realidade mais situações restritivas do que impulsoras no hospital em que atuam, encontrando dificuldade de lidar com as cobranças e pressões no hospital e sem muita disposição para o trabalho coletivo.

Ao finalizar o estudo acreditamos que, o grupo investigado precisa se fortalecer como grupo, aprender a confiar, colaborar e trabalhar em grupo. Assim, será possível a coesão que favorece a harmonia, a integração e a interação, que são elementos importantes que devem estar presentes, para que ocorram mudanças efetivas. Destacamos nesse sentido, que o grupo foi

\section{REFERÊNCIAS}

1. Magalhães AMM, Riboldi CO, Dall'Agnol CM. Planejamento de recursos humanos de enfermagem: desafio para as lideranças. Rev Bras Enferm [Internet]. 2009 [cited 2011 dez 29];62(4):608-12. Available from: http://www.scielo.br/pdf/reben/v62n4/20.pdf.

2. Silva MA, Erdmann AL, Cardoso RS. O sistema de enfermagem hospitalar: visualizando o cenário das políticas gerenciais. Rev. Eletr. Enf. [Internet]. 2008 [cited $2011 \mathrm{dez} 29$ ];10(2):448-59. Available

http://www.fen.ufg.br/revista/v10/n2/v10n2a16.htm.

from:

3. Cardoso MLAP, Ramos LH, D'Innocenzo M. Liderança Coaching: um modelo de referência para o exercício do enfermeiro-líder no contexto hospitalar. Rev Esc Enferm USP [Internet]. 2011 [cited $2011 \mathrm{dez}$ 29];45(3):730-7. Available from: http://www.scielo.br/pdf/reeusp/v45n3/v45n3a26.pdf.

4. Furukawa PO, Cunha ICKO. Profile and competencies of nurse managers at accredited hospitals. Rev Lat Am Enfermagem [Internet]. 2011 [cited $2011 \mathrm{dez} 29$ ];19(1):106-14. Available from: http://www.scielo.br/pdf/rlae/v19n1/15.pdf.

5. Peres AM, Ciampone MHT. Gerência e competências gerais do enfermeiro. Texto Contexto Enferm [Internet]. 2006 [cited 2011 dez 29];15(3):492-9. Available from: http://www.scielo.br/pdf/tce/v15n3/v15n3a15.pdf.

6. Miller K, Riller W, Davis D. Identifying key nursing and team behaviours to achieve high rellabillity. J Nurs Manag. 2009; 17(2):247-55.

7. Bernardes A, Cecilio LCO, Évora YDM, Gabriel CS, Carvalho MB. Collective and decentralized management model in public hospitals: perspective of the nursing team. Rev Lat Am Enfermagem [Internet]. 2011 [cited $2011 \mathrm{dez} 29$ ];19(4):100310. Available from: http://www.scielo.br/pdf/rlae/v19n4/20.pdf. 8. Rocha ESB, Trevizan MA. Quality management at a hospital's nursing service. Rev Lat Am Enfermagem [Internet]. 2009 [cited valente ao se enfrentar no espelho das interações grupais em torno das 80 horas de trabalho.

De qualquer forma, o grupo concluiu o trabalho tendo mais clareza de suas limitações e potencialidades. Nos encontros finais, vários depoimentos mostraram esforços isolados no sentido de implementar o aprendizado à prática, pareciam uma luz de que o investimento, de certa forma, se concretizava em ações pontuais. A partir da intervenção o grupo tem elementos para fazer novos empreendimentos em direção a transformação do modelo de gestão, que precisará necessariamente, contar também com uma mudança na cultura organizacional.

Finalmente, ressaltamos que a pesquisa ação mostrou-se uma ferramenta muito eficiente no processo de qualificação dos enfermeiros gerentes, pois possibilitou avançar para além da dimensão cognitiva que envolve o aprendizado gerencial. O CAV, nesse sentido, foi fundamental para mobilizar as forças impulsoras e restritivas do grupo, mostrando ao vivo e a cores aos profissionais suas limitações e fortalezas. Por trabalhar no nível emocional e cognitivo, o ciclo da aprendizagem vivencial torna o aprendizado significativo e transformador.

2011 dez 29];17(2):240-5. Available from: http://www.scielo.br/pdf/rlae/v17n2/pt 16.pdf.

9. Trevizan MA, Mendes IAC, Hayashida M, Godoy S, Nogueira MS. La búsqueda del compromiso actitudinal: tendencia de la conducta ética del enfermero gerente. Rev Esc Enferm USP [Internet]. 2009 [cited $2011 \mathrm{dez} 29$ ];43(3):721-5. Available from: http://www.scielo.br/pdf/reeusp/v43n3/a31v43n3.pdf. 10. Resck ZMR, Gomes ELR. Background and managerial practice of nurses: paths for transforming práxis. Rev Lat Am Enfermagem [Internet]. 2008 [cited $2011 \mathrm{dez} 29$ ];16(1):71-7. Available from: http://www.scielo.br/pdf/rlae/v16n1/11.pdf.

11. Motta KABM. Análise de um Programa Desenvolvimento de Enfermeiros Gerentes em um Hospital Público na Perspectiva da Pesquisa Ação [thesis]. Goiânia: Faculdade de Medicina/UFG; 2010. 156 p.

12. Marques CMS, Egry EY. The competencies of health professionals and the ministerial policies. Rev ESC Enferm USP [Internet]. 2011 [cited $2011 \mathrm{dez} 29$ ];45(1):187-93. Available from: http://www.scielo.br/pdf/reeusp/v45n1/en 26.pdf.

13. Munari DB, Nunes FC, Motta KAMB, Esperidião E, Silva JI, Coelho MA. Educação de Laboratório como ferramenta no processo educação continuada de enfermeiros gerentes. Rev. enferm. UER] [Internet]. 2008 [cited $2011 \mathrm{dez} 29$ ];16(4):57783. Available from: http://www.facenf.uerj.br/v16n4/v16n4a20.pdf.

14. Guerra ST, Prochnow AG, Trevizan MA, Guido LA. Conflict in nursing management in the hospital context. Rev Lat Am Enfermagem [Internet]. 2011 [cited $2011 \mathrm{dez} 29$ ];19(2):362-9. Available from: http://www.scielo.br/pdf/rlae/v19n2/19.pdf.

15. Thiollent M. Metodologia da pesquisa-ação. São Paulo: Cortez; 2007.

16. Lewin K. Dinâmica de grupo. São Paulo: Cultrix; 1948.

17. Moscovici F. Desenvolvimento interpessoal. Rio de Janeiro: José Olympio; 2008. 
18. Gramigna MRM. Jogos de empresa e técnicas vivenciais. São Paulo: Makron Books; 1995.

19. Mota KAMB, Munari DB. Um olhar para a dinâmica do coordenador de grupos. Rev. Eletr. Enf. [Internet]. 2006 [cited 2011 dez 29];8(1):150-61. Available from: http://www.fen.ufg.br/revista/revista8 1/atualizacao.htm.

20. Jericó MC, Peres AM, Kurcgant P. Estrutura organizacional do serviço de enfermagem: reflexões sobre a influência do poder e da cultura organizacional. Rev Esc Enferm USP [Internet]. 2008 [cited 2011 dez 29];42(3):569-77. Available from: http://www.scielo.br/pdf/reeusp/v42n3/v42n3a21.pdf.

Artigo recebido em 23.03.2010.

Aprovado para publicação em 19.11.2011.

Artigo publicado em 31.12.2011. 